\title{
Can magnetic resonance imaging replace conventional computerized tomography for follow-up of patients with testicular cancer? A systematic review
}

\author{
Jonas Busch ${ }^{1,2}$ (I) Stefanie Schmidt ${ }^{3}$. Peter Albers ${ }^{4}$. Julia Heinzelbecker ${ }^{5}$. Sabine Kliesch ${ }^{6}$. Julia Lackner ${ }^{3}$. \\ David Pfister $^{7} \cdot$ Christian Ruf $^{8} \cdot$ Christian Winter $^{9} \cdot$ Friedemann Zengerling $^{10} \cdot$ Dirk Beyersdorff $^{11}$
}

Received: 2 July 2021 / Accepted: 5 January 2022 / Published online: 17 January 2022

(c) The Author(s) 2022

\begin{abstract}
Purpose Follow-up protocols for patients with testicular cancer (TC) have significantly reduced the number of cross-sectional imaging studies to reduce radiation exposure. At present, it is unclear whether magnetic resonance imaging (MRI) could replace conventional computerized tomography (CT) imaging. The objective of this study is to summarize the scientific evidence on this topic and to review guideline recommendations with regard to the use of MRI.

Methods A systematic literature review was performed searching Medline and Cochrane databases for prospective studies on patients with TC in the follow-up care (last search in February 2021). Additionally, guideline recommendations for TC were screened. Data extraction and quality assessment of included studies were performed and used for a descriptive presentation of results.

Results A total of four studies including two ongoing trials were identified. Overall, the scientific evidence of prospective comparative studies is based on 102 patients. Data suggest that abdominal imaging with MRI can replace conventional CT for detection of lymph node metastasis of the retroperitoneum to spare radiation exposure and contrast media application. However, experienced radiologists are needed. Clinical guidelines are aware of the risk of diagnosis-induced secondary malignancy due to CT imaging and some have adapted their recommendations accordingly. Results of the two ongoing trials on 738 patients are expected soon to provide more reliable results on this topic.

Conclusions There is growing evidence that abdominopelvic MRI imaging can replace CT imaging during follow-up of patients with TC in order to reduce radiation exposure and diagnosis-induced secondary malignancy.
\end{abstract}

Keywords Testicular cancer $\cdot$ Follow-up care $\cdot$ Computerized tomography imaging $\cdot$ Magnetic resonance imaging . Recurrence $\cdot$ Metastasis

Jonas Busch

Jonas.busch@vivantes.de

1 Department of Urology, Charité Universitaetsmedizin Berlin, Berlin, Germany

2 Department of Urology, Vivantes Klinikum Am Urban, Dieffenbachstr. 1, 10967 Berlin, Germany

3 UroEvidence@Deutsche Gesellschaft Für Urologie, Berlin, Germany

4 Department of Urology, University Hospital Düsseldorf, Düsseldorf, Germany

5 Department of Urology and Paediatric Urology, Saarland University Medical Centre and Saarland University Faculty of Medicine, Homburg, Saar, Germany

6 Department of Clinical and Surgical Andrology, Centre of Reproductive Medicine and Andrology, University Hospital, Münster, Münster, Germany
7 Department of Urology, University Hospital Cologne, Cologne, Germany

8 Department of Urology, Bundeswehrkrankenhaus (German Federal Armed Forces Hospital), Koblenz, Germany

9 Urologie Neandertal (Regional Joint Practice), Erkrath, Germany

10 Department of Urology, University Hospital Ulm, Ulm, Germany

11 Clinic and Polyclinic for Diagnostic and Interventional Radiology and Nuclear Medicine, University Hospital Hamburg-Eppendorf, Hamburg, Germany 


\section{Introduction}

Currently, there is no standardized international consensus on follow-up schemes for patients with testicular cancer (TC) in full remission after curative therapy. The aim of regular follow-up examinations is the detection of recurrences, as well as the early detection of late effects (harms) from previous treatment(s). But to date, there are significant differences in the recommendations from international clinical practice guidelines concerning the frequency and type of imaging procedures [1-3].

Usually, follow-up examinations after curative therapy include a clinical examination including the determination of body mass index and blood pressure and a sonography examination of the remaining testis, especially if no contralateral testicle biopsy has been performed in younger patients $(<30$ years) and in patients with small testicle volume ( $<12 \mathrm{ml})$ [4-6]. Sonography of the residual testicular parenchyma is also mandatory in organ-preserving procedures after tumor resection.

In addition, the control of serum tumor markers, chest $\mathrm{X}$-ray imaging and abdominal and pelvic sectional imaging are generally recommended [4-6]. However, the routine use of a thoracic X-ray examination is currently questioned, especially in stage I disease, due to the late effects of radiation exposure [7]. Additionally, an expanded blood count with determination of testosterone, luteinizing hormone (LH) and lipid values should be performed once a year [8]. Further examinations should be discussed with the patient and depend on individual conditions and prior treatments.

Traditionally, computerized tomography (CT) scans (especially contrast-enhanced CTs CECT as the most sensitive) of the abdomen and pelvis are the imaging procedures of choice for the detection of retroperitoneal lymph node metastasis or recurrence, mainly because of high reproducibility and excellent imaging of the para-aortic and paracaval regions. Difficulties in diagnosis with CT scans might arise in men with little retroperitoneal fat, which tend to be an impediment for the correct interpretation of results, and might also provide false-negative results in up to $30 \%$ of cases, due to difficulties in the interpretation of lymph nodes based on morphology and size alone $[9,10]$. The greatest concern, however, is the radiation exposure in patients with testicular cancer undergoing several repeated cross-sectional imaging at a young age, which is associated with a significant risk of secondary malignancies in the upcoming years [11]. The reference values (CTDI Vol) for an examination of the upper abdomen and lower abdomen with pelvis are each given as $15 \mathrm{mGy}$. A complete abdominal imaging from the upper abdomen to the pelvis, thus, typically reaches an effective dose of $10 \mathrm{mSv}$.
Therefore, magnetic resonance imaging (MRI) might be an alternative to CT scans. MRI scans were usually restricted to patients with contraindications to CT or to whom intravenous contrast media cannot be given $[9,10,12]$, as they do not provide additional clinical information over $\mathrm{CT}$ scans. However, improved MRI technique, e. g. diffusion-weighted imaging, is a MRI technique that improves the identification of lymph nodes on the basis of degree of restricted diffusion, but it is still limited by significant overlap between benign and malignant lymph nodes [13]. Further general disadvantages of MRI are longer examination time, higher costs, and lower availability in the medical setting [14]. Side effects such as systemic nephrogenic fibrosis and intracerebral gadolinium (Gd) deposition are only to be expected with severely impaired glomerular filtration rate but appear extremely rare due to the switch to macrocyclic Gd contrast media.

In 2009, a literature review of Hansen et al. did not reveal valid data regarding the diagnostic accuracy of MRI imaging compared with current multislice CT for the diagnosis of retroperitoneal spread in testicular cancer [15]. However, the latest updates of several clinical practice guidelines include modifications concerning the frequency of a CT scan in favor of an MRI examination, as replacing CT by MRI scan would reduce the overall radiation exposure and, therefore, the risk of a radiation-induced second cancer, especially when using repeated cross-sectional imaging in men at a young age.

The purpose of this study was to update the evidence and review whether MRI could replace conventional CT imaging in patients with TC after curative therapy.

\section{Methods}

This work was based on a systematic literature search that was conducted for the elaboration of the first German clinical practice guideline $[3,16]$. In this context, several systematic literature searches were conducted. Here, we present the results combined with an updated search.

\section{Systematic literature search}

We performed a systematic literature review to identify studies comparing the use of MRI versus CT scan in the follow-up care of men ( $\geq 18$ years) with a proven diagnosis of TC after primary therapy. We used the biomedical databases Medline (via Ovid) and Cochrane Central Register of Controlled Trials (search period January 2010 to February 2021). Our search was limited to full text publications and to those written in English and German language. We considered clinical trials and prospective observational studies. Case control studies, case reports, case series, editorials, 
comments and conference abstracts were excluded. An additional search for unpublished data and ongoing studies was conducted in clinical trial registers (clinicaltrial.gov/ and www.who.int/ictrp/). We contacted the study coordinators in case of missing information for studies identified in the trial registries and hand-searched the reference lists of included studies to determine additional, potentially relevant studies.

We also searched for clinical practice guidelines in order to analyze how current evidence is translated into clinical recommendations. Therefore, we consulted well-known institutions, which provided clinical practice guidelines in the field of urology and downloaded these.

\section{Literature screening, data extraction and quality assessment}

One review author screened the titles and abstracts and afterwards the full texts of the retrieved references and determined the relevance for inclusion. For included studies, one author extracted relevant data in evidence tables. The study quality was determined using the QUADAS-2 tool for the assessment of diagnostic accuracy [17] and the level of evidence was rated according to the Oxford criteria [18]. Clinical practice guidelines were rated with the AGREE II tool [19]. Only guidelines were reported showing a minimum quality standard of at least 50 points. In any case of uncertainty another review author was involved in each of the above-mentioned steps and a consensus was reached by discussion.

\section{Results}

\section{Evidence from primary studies}

Our systematic literature review identified four prospective studies, which compared MRI to CT (Laukka et al. [20], Sohaib et al. [21], TRISST trial [22], TENY trial [23]) (Table 1; Fig. 1). The Sohaib study was added because of its high relevance although it was initially not included in the search period.

Laukka et al. conducted an intraindividual comparative study of MRI and CT examinations in 50 patients with TC [20]. They obtained comparable results with both methods, CT and MRI. In this study, MRI was also performed with diffusion imaging but without contrast agent application. All 46 patients with retroperitoneal metastases could be detected with both techniques. The differences related to individual lymph nodes were not statistically significant [20].

Sohaib et al. [21] conducted a prospective diagnostic study in the UK with a 6-week follow-up (level $2 \mathrm{~b}$ evidence). 52 patients were included with a mean age of 34 years. 22 patients initially presented with stage I disease, 30 patients with retroperitoneal nodes. The authors certify a sensitivity of $97 \%$ for the detection of retroperitoneal lymph nodes for MRI imaging [95\% confidence interval (CI) of 80-100\%]. However, the results of the sensitivity analysis differed by the grade of experience of the performing radiologist. A trainee radiologist with 1-year experience yielded a sensitivity of $80 \%$ (95\% CI of $61-92 \%$ ).

The TRISST trial (NCT00589537) is a randomized trial with a 5-year follow-up and the aim of assessing whether a reduced CT schedule or MRI could be used as safe and effective alternatives to standard CT-based surveillance. The investigators plan to recruit 660 patients with stage I seminoma disease. The design of the trial includes four interventions [24]. Two arms will each use CT scan of the abdomen/ retroperitoneum and 2 arms will use MRI scan of the abdomen/retroperitoneum. The two arms of the same intervention differ in terms of the follow-up protocol $(6,12,18,24$, 36 months versus $6,12,18,24,36,48$, and 60 months). Recruitment was finished in 2014. Formal publication is planned for August 2021.

The TENY trial (NCT03436901), is a diagnostic openlabel study conducted in Denmark. The study authors aim to include 78 TC patients with stage II-III disease. They try to replace CT as a follow-up imaging method with nonionizing whole-body MRI including diffusion-weighted imaging. The study is currently recruiting patients. Results are expected earliest in August 2021.

\section{Recommendations from consensus conferences and clinical practice guidelines in the change of time}

The literature review of clinical practice guidelines showed 9 results (Table 2). After applying the minimum quality criteria, 6 guidelines remained and are discussed in the following. We also provide information on our German guideline.

Between 2010 and 2014, the Belgian Health Care Knowledge Center (KCE), the Scottish Intercollegiate Guidelines Network (SIGN) and the Cancer Care Ontario (CCO) clinical practice guidelines recommended CT scans as the primary diagnostic imaging modality for TC $[25,26]$. These recommendations were accompanied by precautions that should be taken to avoid iodine allergy or nephrotoxicity as an adverse event in patients. For these patients, MRI could be an alternative follow-up technique.

In 2018, an European Society of Medical Oncology (ESMO) consensus conference on testicular cancer readdressed the role of MRI versus CT in TC patients. Three recommendations were made for the use of MRI during staging and for post-treatment assessment of TC [27]:

- MRI may be helpful for characterization of equivocal CT findings (e.g., in liver, bone, brain). (Level of evidence: 


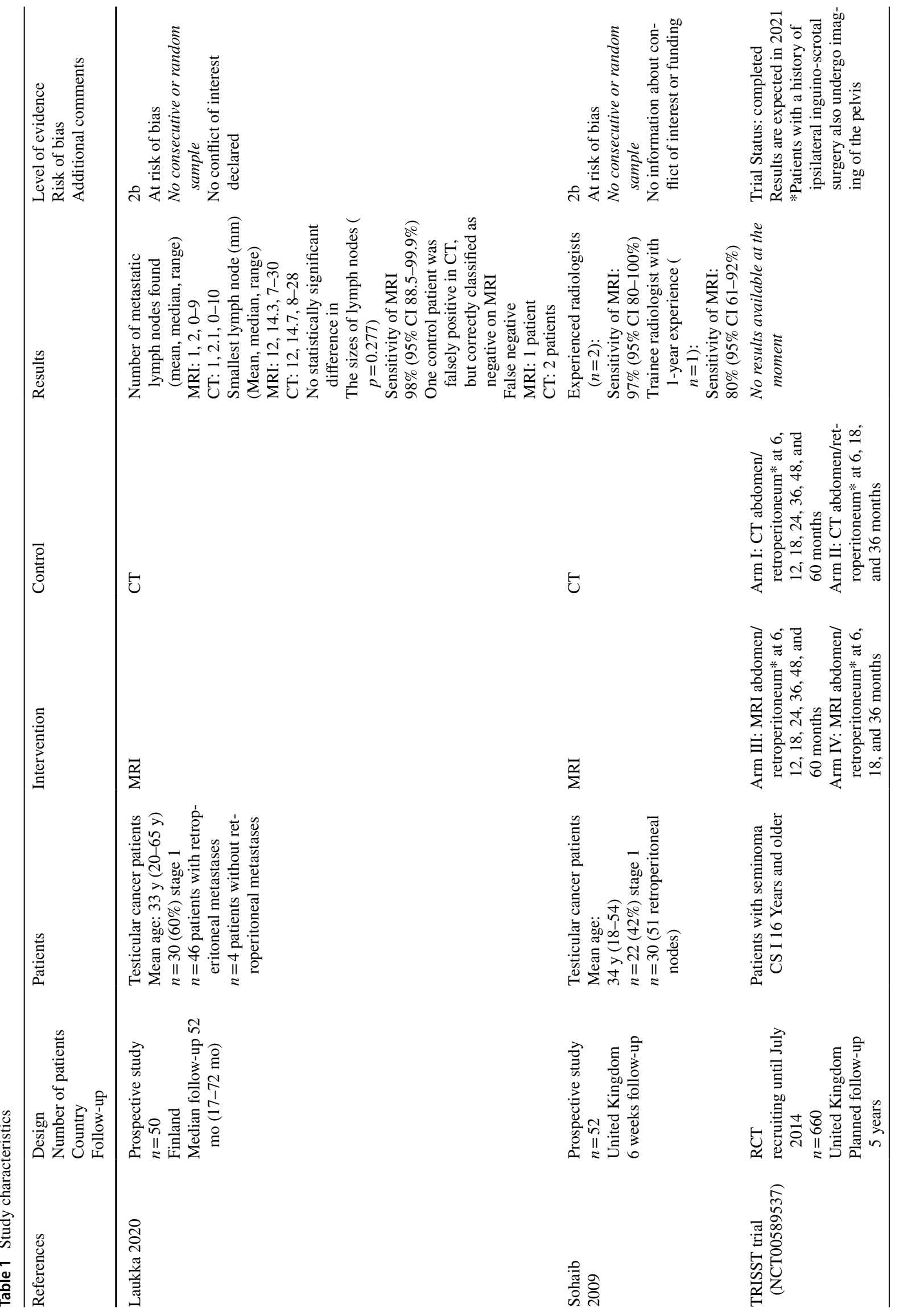


IV; Strength of recommendation: A; Level of consensus: No vote obtained)

- MRI is not routinely recommended in all patients for staging of the retroperitoneum. (Level of evidence: III; Strength of recommendation: B; Level of consensus: 94.1\% (32) yes, $5.9 \%$ (2) abstain (34 voters))

- An MRI can be recommended for follow-up of the retroperitoneum, if standard protocols are used and the results are reported by an experienced radiologist. [Level of evidence: III; Strength of recommendation: A; Level of consensus: $85.3 \%$ (29) yes, $2.9 \%$ (1) no, $11.8 \%$ (4) abstain (34 voters)].

The European Association of Urology (EAU) clinical guideline from 2020 recommended contrast-enhanced CT as the most sensitive means to evaluate the thorax, abdomen and pelvis for initial TC staging. Contrast enhanced CT (CECT) was recommended in all patients for staging before orchidectomy but may be postponed until histopathological confirmation of malignancy [2]. For abdominal staging purposes, similar accuracy was shown for CECT in the detection of retroperitoneal nodal enlargement [21,28]. The EAU stated that MRI is subject to greater artefacts and is not routinely indicated. If CT is contraindicated because of allergy to iodine-based contrast media, non-contrast CT may be performed to evaluate nodal size. Currently, there are no indications for routine use of MRI for TC staging. MRI should be used to screen for brain metastases [2, 29, 30].

The German clinical guideline on TC provides separate follow-up schemes for the different stages and types of TC [3]. In view of the lack of evidence, the guideline panel published a recommendation based on interdisciplinary expert consensus: MRI of the abdomen/pelvis should replace the $\mathrm{CT}$ of the abdomen/pelvis in the follow-up care of patients with TC if performed at centers with proven experience to reduce radiation exposure. Experienced radiologists are required for the interpretation of results.

The 2020 National Cancer Care Network (NCCN) guideline on TC recommends abdominal/pelvic CT scan for follow-up examinations [1]. In select circumstances, an MRI can be considered to replace an abdominal/pelvic CT scan. The MRI protocol should include visualization of the retroperitoneal and pelvic nodes and should be performed in experienced centers in interpreting MRI results for testicular cancer. The same imaging modality (CT or MRI) should be used throughout follow-up.

\section{Discussion}

Within this systematic review, the evidence based on prospective studies regarding the question whether MRI could replace conventional $\mathrm{CT}$ imaging in patients with $\mathrm{TC}$ after 
Fig. 1 Study flow diagram of identified references
Table 2 Quality assessment of included clinical practice guidelines

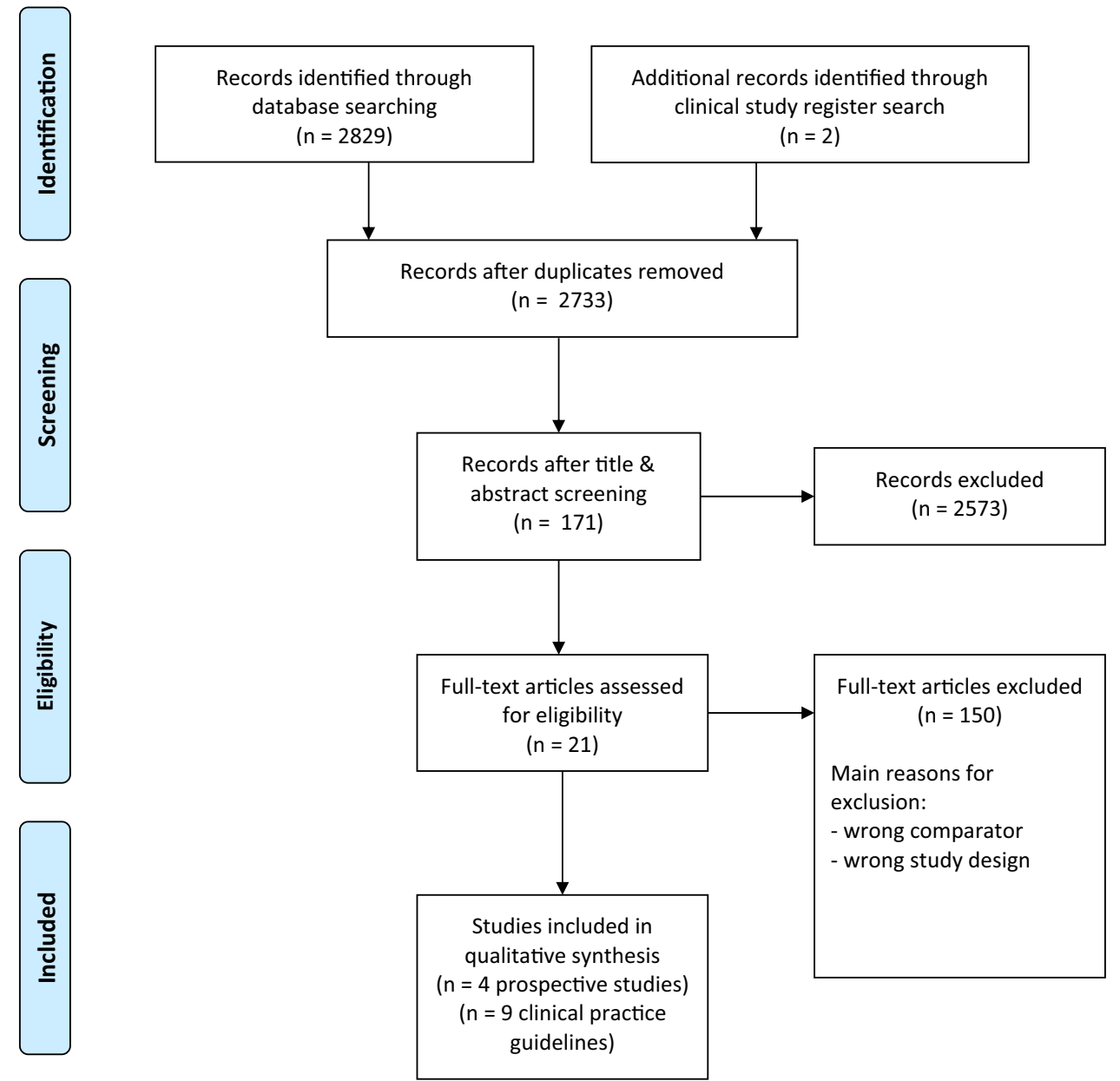

\begin{tabular}{ll}
\hline Clinical practice guideline & Quality assessment \\
\hline European Association of Urology (EAU) 2020 & $65 / 100$ \\
National Cancer Care Network (NCCN) 2020 & $54 / 100$ \\
European Society of Medical Oncology (ESMO) 2019 & $53 / 100$ \\
American College of Radiology (ACR) 2016 & $30 / 100$ \\
Alberta Health Services (AHS) 2016 & $48 / 100$ \\
Cancer Care Ontario (CCO) 2014 & $65 / 100$ \\
European Society of Medical Oncology (ESMO) 2013 & $34 / 100$ \\
Scottish Intercollegiate Guidelines Network (SIGN) 2011 & $82 / 100$ \\
Belgian Health Care Knowledge Center (KCE) 2010 & $71 / 100$ \\
\hline
\end{tabular}

curative therapy is summarized. Two prognostic studies with data on 102 patients showed that the interpretation of MRI scans by experienced radiologists showed a good sensitivity for the detection of retroperitoneal lymph nodes. Results of two ongoing clinical trials (including further patients 738) are expected urgently and might change follow-up schemes of patients with TC in the future.

Several additional studies, which did not match our inclusion criteria, have demonstrated the value of diffusion imaging for the detection of pathologically altered clinical stage (CS) in the setting of tumor disease and specifically germ cell tumors [31, 32]. In a retrospective single center analysis, Larsen et al. demonstrated in 759 consecutive patients that MRI follow-up is routinely possible for patients with TC CS I. The only exception was one patient with claustrophobia. The examination had to be terminated incompletely. Examination time was under $30 \mathrm{~min}$ in this setting with coronal T1-weighted images, axial T2-weighted 
and diffusion-weighted images. Contrast administration was omitted. For the detection of recurrence, a specificity of $97.4 \%$ and a sensitivity of $93.8 \%$ could be achieved for the retroperitoneum and pelvis [31]. The sensitivity for detecting relapse $\geq 10 \mathrm{~mm}$ in short axis lymph node diameter was $100 \%$. The negative predictive value was $99.7 \%$, the positive predictive value was $59.9 \%$ and the accuracy was $97.3 \%$. The authors concluded that MRI of the retroperitoneum and pelvis constitutes a safe alternative to $\mathrm{CT}$ in the follow-up of patients with TC CS I with both a high sensitivity and a high specificity. They presented a robust MRI protocol with diffusion-weighted imaging and estimate that MRI followup of TC CS I can be easily implemented in most modern radiology departments [31].

Mosavi et al. were able to show that whole-body MRI with diffusion imaging is feasible in 71 patients with TC. However, the examination time was $45 \mathrm{~min}$. In two patients, the examination had to be terminated due to claustrophobia. In this study, additional information could be obtained from diffusion-weighted imaging in two cases. Thus, in one case a residual retroperitoneal lymph node could be identified as such without activity, which would otherwise only be possible with a positron emission tomography-CT (PET-CT). In another case, a small lymph node, in the size standard range, which was conspicuous by its diffusion restriction, could be confirmed as a metastasis in the PET-CT [32].

Recently, a number of papers have been published on follow-up examinations that are risk-adapted to the respective situation with regard to frequency of CT examinations $[6,33,34]$. Depending on the risk assessment, recurrences should be identified at an early stage within the framework of an ideal follow-up while at the same time protecting against unnecessary radiation exposure.

\section{Further evidence on testicular cancer follow-up care}

In a survey among German urologists on the adherence to grade "A" recommendations from the 2015 EAU guideline on TC [35], Nestler et al. [36] demonstrated that MRI of the abdomen was used more frequently in younger patients $(43.9 \% ; n=164)$ and in cases of allergy to contrast media or renal insufficiency $(46.0 \% ; n=172)$. Only $14.2 \%$ of urologists $(n=53)$ always used MRI for abdominal imaging, and MRI was not sufficiently available to $3.5 \%(n=13)$. Similar to the initial imaging modality, MRI for follow-up care was more often used by office urologists than by hospital-based urologists $(19.0 \%$ vs. $5.4 \%, p=0.014)$ and by more experienced urologists ( $>5$ years) $(17.2 \%$ vs. $5.9 \%, p=0.041)$. The authors concluded that MRI is widely available in Germany and a valid option for radiation-free follow-up imaging of the abdomen if performed by radiologists experienced in oncological and abdominal MRI reading [36].

\section{Imaging guidelines on other abdominopelvic tumor entities}

The need for lymph node metastasis detection is also key in other tumor entities. Clinical guideline recommendations may vary among those. The lack of studies comparing MRI and CT imaging is a general trait, although MRI is used in most cancer entities. For bladder cancer staging, Crozier et al. compared the different imaging modalities MRI/PET with conventional CT in a systematic review and meta-analysis [37]. The pooled MRI sensitivity was 0.60 (95\% CI $0.44-0.74)$ and the pooled specificity was 0.91 (95\% CI 0.82-0.96), which is superior compared to CT for detection of positive lymph nodes in bladder cancer prior to cystectomy.

Lohman et al. systematically reviewed the diagnostic accuracy of CT and MRI for the detection of lymph node metastases in gallbladder cancer [38]. Due to a lack of data, no subgroup analysis comparing the diagnostic accuracy of CT vs. MRI could be performed. Therefore, the value of current imaging strategies for the pre-operative assessment of nodal status in gallbladder cancer remains unclear, especially regarding the detection of small lymph node metastasis.

A Cochrane review on melanoma reported that comparative data with CT or MRI are lacking [39]. The increasing availability of adjuvant therapies for people with melanoma at high risk of disease spread at presentation will have a considerable impact on imaging services, yet evidence for the relative diagnostic accuracy of available tests is limited.

For rectal cancer, Gao et al. compared the value of four imaging modalities in diagnosing lymph node involvement [40]. The results of the overview indicated that endoscopic ultrasound had better diagnostic value than CT and endorectal ultrasound in the diagnosis of lymph node invasion. Compared with CT and endorectal ultrasound, MRI was more sensitive. Endorectal ultrasound was more specific when compared to CT. Endoscopic ultrasound and MRI had comparable diagnostic accuracy for evaluating lymph node involvement, but no modality was particularly accurate. However, based on current technology and conditions, endoscopic ultrasound and MRI may be choices for diagnosing lymph node involvement in patients with rectal cancer.

In 2017, Liu et al. published a meta-analysis comparing CT, PET-CT, MRI and diffusion-weighted imaging MRI for detection of lymph node metastases in patients with cervical cancer [41]. The authors concluded that among the four non-invasive modalities, the PET or PET/CT had the highest specificity, and the diffusion-weighted imaging MRI had the highest sensitivity. 


\section{Conclusions}

Data from two small prospective studies suggest that MRI imaging can replace CT imaging during follow-up of patients with TC to reduce radiation exposure and diagnosis-induced secondary malignancy. Results from an ongoing randomized and one open-label study are expected soon and will aid in the decision-making of follow-up care of these patient.

Author contributions JB, SS, JL, DB: Project development, data collection, data analysis, manuscript writing. PA, SK: Project development. JH, DP, CR, CW, FZ: Manuscript writing. JL: Data collection, data analysis, manuscript writing.

Funding Open Access funding enabled and organized by Projekt DEAL. This work is based on a clinical guideline program, which was funded by the German Cancer Aid Foundation (DKH) (Reference No. 70112789).

\section{Declarations}

Conflict of interest All authors certify that they have no affiliations with or involvement in any organization or entity with any financial interest or non-financial interest in the subject matter or materials discussed in this manuscript.

Ethics approval This article does not contain any studies with human or animal subjects performed by the any of the authors.

Open Access This article is licensed under a Creative Commons Attribution 4.0 International License, which permits use, sharing, adaptation, distribution and reproduction in any medium or format, as long as you give appropriate credit to the original author(s) and the source, provide a link to the Creative Commons licence, and indicate if changes were made. The images or other third party material in this article are included in the article's Creative Commons licence, unless indicated otherwise in a credit line to the material. If material is not included in the article's Creative Commons licence and your intended use is not permitted by statutory regulation or exceeds the permitted use, you will need to obtain permission directly from the copyright holder. To view a copy of this licence, visit http://creativecommons.org/licenses/by/4.0/.

\section{References}

1. Gilligan T, Lin DW, Aggarwal R, Chism D, Cost N, Derweesh IH, Emamekhoo H, Feldman DR, Geynisman DM, Hancock SL, LaGrange C, Levine EG, Longo T, Lowrance W, McGregor B, Monk P, Picus J, Pierorazio P, Rais-Bahrami S, Saylor P, Sircar K, Smith DC, Tzou K, Vaena D, Vaughn D, Yamoah K, Yamzon J, Johnson-Chilla A, Keller J, Pluchino LA (2019) Testicular cancer, version 2.2020, NCCN clinical practice guidelines in oncology. J Natl Compr Canc Netw 17(12):1529-1554. https://doi.org/10. 6004/jncen.2019.0058

2. Laguna MP, Albers P, Algaba F, Bokemeyer C, Boormans JL, Fischer S, Fizazi K, Gremmels H, Leão R, Nicolai N, Oldenburg J, Tandstad T (2020) EAU guidelines on testicular cancer 2020. In: European association of urology guidelines. 2020 Edition., vol presented at the EAU Annual Congress Amsterdam 2020. European Association of Urology Guidelines Office, Arnhem, The Netherlands,

3. Kliesch S, Schmidt S, Wilborn D, Aigner C, Albrecht W, Bedke J, Beintker M, Beyersdorff D, Bokemeyer C, Busch J, Classen J, de Wit M, Dieckmann KP, Diemer T, Dieing A, Gockel M, Göckel-Beining B, Hakenberg OW, Heidenreich A, Heinzelbecker J, Herkommer K, Hermanns T, Kaufmann S, Kornmann M, Kotzerke J, Krege S, Kristiansen G, Lorch A, Müller AC, Oechsle K, Ohloff T, Oing C, Otto U, Pfister D, Pichler R, Recken H, Rick O, Rudolph Y, Ruf C, Schirren J, Schmelz H, Schmidberger H, Schrader M, Schweyer S, Seeling S, Souchon R, Winter C, Wittekind C, Zengerling F, Zermann DH, Zillmann R, Albers P (2021) Management of germ cell tumours of the testes in adult patients: German clinical practice guideline, Part II-recommendations for the treatment of advanced, recurrent, and refractory disease and extragonadal and sex cord/stromal tumours and for the management of follow-up, toxicity, quality of life, palliative care, and supportive therapy. Urol Int. https://doi.org/10.1159/000511245

4. Cathomas R, Hartmann M, Krege S, Souchon R, Lorch A, Mayer F, De Santis M, Gillessen S (2011) Interdisciplinary evidencebased recommendations for the follow-up of testicular germ cell cancer patients. Onkologie 34(1-2):59-64. https://doi.org/10. $1159 / 000323346$

5. Hartmann M, Krege S, Souchon R, De Santis M, Gillessen S, Cathomas R (2011) Follow-up of testicular germ cell cancer patients: interdisciplinary evidence-based recommendations. Urologe A 50(7):830-835. https://doi.org/10.1007/ s00120-011-2556-0

6. Souchon R, Hartmann M, Krege S, Lorch A, Mayer F, De Santis M, Gillessen S, Beyer J, Cathomas R (2011) Interdisciplinary evidence-based recommendations for the follow-up of early stage seminomatous testicular germ cell cancer patients. Strahlenther Onkol 187(3):158-166. https://doi.org/10.1007/ s00066-010-2227-x

7. De La Pena H, Sharma A, Glicksman C, Joseph J, Subesinghe M, Traill Z, Verrill C, Sullivan M, Redgwell J, Bataillard E, Pintus E, Dallas N, Gogbashian A, Tuthill M, Protheroe A, Hall M (2017) No longer any role for routine follow-up chest $\mathrm{x}$-rays in men with stage I germ cell cancer. Eur J Cancer 84:354-359. https://doi.org/ 10.1016/j.ejca.2017.07.005

8. Dohle GR, Arver S, Bettocchi C, Jones TH (2018) EAU-Leitlinie Männlicher Hypogonadismus. J Reproduktionsmed Endokrinol 15(2):71-88

9. Krug B, Heidenreich A, Dietlein M, Lackner K (1999) The lymph node staging of malignant testicular germ-cell tumors. Rofo 171(2):87-94

10. Morisawa N, Koyama T, Togashi K (2006) Metastatic lymph nodes in urogenital cancers: contribution of imaging findings. Abdom Imaging 31(5):620-629. https://doi.org/10.1007/ s00261-005-0244-5

11. Tarin TV, Sonn G, Shinghal R (2009) Estimating the risk of cancer associated with imaging related radiation during surveillance for stage I testicular cancer using computerized tomography. J Urol 181(2):627-632. https://doi.org/10.1016/j.juro.2008.10.005

12. Heidenreich A, Albers P, Classen J, Graefen M, Gschwend J, Kotzerke J, Krege S, Lehmann J, Rohde D, Schmidberger H, Uder M, Zeeb H (2010) Imaging studies in metastatic urogenital cancer patients undergoing systemic therapy: recommendations of a multidisciplinary consensus meeting of the association of urological oncology of the German cancer society. Urol Int 85(1):1-10. https://doi.org/10.1159/000318985

13. Hedgire SS, Pargaonkar VK, Elmi A, Harisinghani AM, Harisinghani MG (2012) Pelvic nodal imaging. Radiol Clin N Am 50(6):1111-1125. https://doi.org/10.1016/j.rcl.2012.08.002 
14. Yacoub JH, Oto A, Allen BC, Coakley FV, Friedman B, Hartman MS, Hosseinzadeh K, Porter C, Sahni VA, Sudakoff GS, Verma S, Wang CL, Remer EM, Eberhardt SC (2016) ACR appropriateness criteria staging of testicular malignancy. J Am Coll Radiol 13(10):1203-1209. https://doi.org/10.1016/j.jacr.2016.06.026

15. Hansen J, Jurik AG (2009) Diagnostic value of multislice computed tomography and magnetic resonance imaging in the diagnosis of retroperitoneal spread of testicular cancer: a literature review. Acta Radiol 50(9):1064-1070. https://doi.org/10.3109/ 02841850903220371

16. Kliesch S, Schmidt S, Wilborn D, Aigner C, Albrecht W, Bedke J, Beintker M, Beyersdorff D, Bokemeyer C, Busch J, Classen J, de Wit M, Dieckmann KP, Diemer T, Dieing A, Gockel M, Göckel-Beining B, Hakenberg OW, Heidenreich A, Heinzelbecker J, Herkommer K, Hermanns T, Kaufmann S, Kornmann M, Kotzerke J, Krege S, Kristiansen G, Lorch A, Müller AC, Oechsle K, Ohloff T, Oing C, Otto U, Pfister D, Pichler R, Recken H, Rick O, Rudolph Y, Ruf C, Schirren J, Schmelz H, Schmidberger H, Schrader M, Schweyer S, Seeling S, Souchon R, Winter C, Wittekind C, Zengerling F, Zermann DH, Zillmann R, Albers P (2021) Management of germ cell tumours of the testis in adult patients. german clinical practice guideline part I: epidemiology, classification, diagnosis, prognosis, fertility preservation, and treatment recommendations for localized stages. Urol Int. Doi: https://doi. org/10.1159/000510407

17. Whiting PF, Rutjes AW, Westwood ME, Mallett S, Deeks JJ, Reitsma JB, Leeflang MM, Sterne JA, Bossuyt PM (2011) QUADAS-2: a revised tool for the quality assessment of diagnostic accuracy studies. Ann Intern Med 155(8):529-536. https://doi. org/10.7326/0003-4819-155-8-201110180-00009

18. Oxford Centre for Evidence-Based Medicine (2009) Levels of evidence (March 2009). https://www.cebm.net/2009/06/oxfordcentre-evidence-based-medicine-levels-evidence-march-2009/.

19. Brouwers MC, Kho ME, Browman GP, Burgers JS, Cluzeau F, Feder G, Fervers B, Graham ID, Grimshaw J, Hanna SE, Littlejohns P, Makarski J, Zitzelsberger L (2010) AGREE II: advancing guideline development, reporting and evaluation in health care. CMAJ 182(18):E839-842. https://doi.org/10.1503/cmaj.090449

20. Laukka M, Mannisto S, Beule A, Kouri M, Blomqvist C (2020) Comparison between CT and MRI in detection of metastasis of the retroperitoneum in testicular germ cell tumors: a prospective trial. Acta Oncol 59(6):660-665. https://doi.org/10.1080/02841 86x.2020.1725243

21. Sohaib SA, Koh DM, Barbachano Y, Parikh J, Husband JE, Dearnaley DP, Horwich A, Huddart R (2009) Prospective assessment of MRI for imaging retroperitoneal metastases from testicular germ cell tumours. Clin Radiol 64(4):362-367. https://doi.org/ 10.1016/j.crad.2008.10.011

22. NCT00589537 Magnetic resonance imaging and computed tomography in patients with Stage I seminoma of the testicle. https://clinicaltrials.gov/ct2/show/NCT00589537.

23. NCT03436901 Whole body MRI with DWI for monitoring patients treated for testicular cancer stage II-III (TENY). https:// clinicaltrials.gov/ct2/show/NCT03436901.

24. Cafferty FH, Gabe R, Huddart RA, Rustin G, Williams MP, Stenning SP, Bara A, Bathia R, Freeman SC, Alder L, Joffe JK (2012) UK management practices in stage I seminoma and the Medical Research Council Trial of Imaging and Schedule in Seminoma Testis managed with surveillance. Clin Oncol (R Coll Radiol) 24(1):25-29. https://doi.org/10.1016/j.clon.2011.09.005

25. KCE (2010) Wetenschappelijke ondersteuning van het College voor Oncologie: een update van de nationale richtlijn voor testiskanke, vol KCE Reports 142A. Good Clinical Practice (GCP). Federaal Kenniscentrum voor de Gezondheidszorg (KCE), Brussel
26. SIGN (2011) Management of adult testicular germ cell tumours. A national clinical guideline. SIGN publication; no. 12463, Edinburgh (Scotland): Scottish Intercollegiate Guidelines Network (SIGN)

27. Honecker F, Aparicio J, Berney D, Beyer J, Bokemeyer C, Cathomas R, Clarke N, Cohne-Cdermark G, Daugaard G, Dieckmann KP, Fizazi K, Fosså S, Germa-Lluch JR, Giannatempo P, Gietema JA, Gillessen S, Haugnes HS, Heidenreich A, Hemminki K, Huddart R, Jewett MAS, Joly F, Lauritsen J, Lorch A, Necchi A, Nicolai N, Oing C, Oldenburg J, Ondruš D, Papachristofilou A, Powles T, Sohaib A, Ståhl O, Tandstad T, Toner G, Horwich A (2018) ESMO Consensus Conference on testicular germ cell cancer: diagnosis, treatment and follow-up. Ann Oncol 29(8):1658-1686. Doi: https://doi.org/10.1093/annonc/mdy217

28. Pierorazio PM, Cheaib JG, Tema G, Patel HD, Gupta M, Sharma R, Zhang A, Bass EB (2020) Performance characteristics of clinical staging modalities for early stage testicular germ cell tumors: a systematic review. J Urol 203(5):894-901. https://doi.org/10. 1097/ju.0000000000000594

29. Fink KR, Fink JR (2013) Imaging of brain metastases. Surg Neurol Int 4(Suppl 4):S209-219. https://doi.org/10.4103/2152-7806. 111298

30. Pope WB (2018) Brain metastases: neuroimaging. Handb Clin Neurol 149:89-112. https://doi.org/10.1016/b978-0-12-811161-1. 00007-4

31. Larsen SKA, Agerbæk M, Jurik AG, Pedersen EM (2020) Ten years of experience with MRI follow-up of testicular cancer stage I: a retrospective study and an MRI protocol with DWI. Acta Oncol 59(11):1374-1381. https://doi.org/10.1080/0284186x. 2020.1794035

32. Mosavi F, Laurell A, Ahlström H (2015) Whole body MRI, including diffusion-weighted imaging in follow-up of patients with testicular cancer. Acta Oncol 54(10):1763-1769. https://doi. org/10.3109/0284186x.2015.1043027

33. Cathomas R, Helbling D, Stenner F, Rothermundt C, Rentsch C, Shahin O, Seifert HH, Zaugg K, Lorch A, Mayer F, Beyer J, De Santis M, Gillessen S (2010) Interdisciplinary evidence-based recommendations for the follow-up of testicular cancer patients: a joint effort. Swiss Med Wkly 140(25-26):356-369

34. van As NJ, Gilbert DC, Money-Kyrle J, Bloomfield D, Beesley S, Dearnaley DP, Horwich A, Huddart RA (2008) Evidence-based pragmatic guidelines for the follow-up of testicular cancer: optimising the detection of relapse. Br J Cancer 98(12):1894-1902. https://doi.org/10.1038/sj.bjc.6604280

35. Albers P, Albrecht W, Algaba F, Bokemeyer C, Cohn-Cedermark G, Fizazi K, Horwich A, Laguna MP, Nicolai N, Oldenburg J (2015) Guidelines on testicular cancer: 2015 update. Eur Urol 68(6):1054-1068. https://doi.org/10.1016/j.eururo.2015.07.044

36. Nestler T, Baunacke M, Dräger D, von Landenberg N, Groeben C, Huber J (2019) Testicular cancer guideline adherence and patterns of care in Germany: a nationwide survey. Eur J Cancer Care (Engl) 28(1):e12917. https://doi.org/10.1111/ecc.12917

37. Crozier J, Papa N, Perera M, Ngo B, Bolton D, Sengupta S, Lawrentschuk N (2019) Comparative sensitivity and specificity of imaging modalities in staging bladder cancer prior to radical cystectomy: a systematic review and meta-analysis. World J Urol 37(4):667-690. https://doi.org/10.1007/s00345-018-2439-8

38. de Savornin Lohman EAJ, van der Geest LG, de Bitter TJJ, Nagtegaal ID, van Laarhoven C, van den Boezem P, van der Post CS, de Reuver PR (2020) Re-resection in incidental gallbladder cancer: survival and the incidence of residual disease. Ann Surg Oncol 27(4):1132-1142. https://doi.org/10.1245/ s10434-019-08074-4

39. Dinnes J, Ferrante di Ruffano L, Takwoingi Y, Cheung ST, Nathan P, Matin RN, Chuchu N, Chan SA, Durack A, Bayliss SE, Gulati A, Patel L, Davenport C, Godfrey K, Subesinghe M, Traill Z, 
Deeks JJ, Williams HC (2019) Ultrasound, CT, MRI, or PET-CT for staging and re-staging of adults with cutaneous melanoma. Cochrane Database Syst Rev 7(7):Cd012806. https://doi.org/10. 1002/14651858.CD012806.pub2

40. Gao Y, Li J, Ma X, Wang J, Wang B, Tian J, Chen G (2019) The value of four imaging modalities in diagnosing lymph node involvement in rectal cancer: an overview and adjusted indirect comparison. Clin Exp Med 19(2):225-234. https://doi.org/10. 1007/s10238-019-00552-Z

41. Liu B, Gao S, Li S (2017) A comprehensive comparison of CT, MRI, positron emission tomography or positron emission
tomography/CT, and diffusion weighted imaging-mri for detecting the lymph nodes metastases in patients with cervical cancer: a meta-analysis based on 67 studies. Gynecol Obstet Invest 82(3):209-222. https://doi.org/10.1159/000456006

Publisher's Note Springer Nature remains neutral with regard to jurisdictional claims in published maps and institutional affiliations. 